\title{
Paleobiogeography: The Relevance of Fossils to Biogeography
}

\author{
Bruce S. Lieberman \\ Department of Geology and Department of Ecology and Evolutionary Biology, \\ University of Kansas, Lawrence, Kansas 06045; email: blieber@ku.edu
}

Key Words biogeography, geo-dispersal, vicariance, phylogenetics, extinction

- Abstract Paleobiogeography has advanced as a discipline owing to the increasing utilization of a phylogenetic approach to the study of biogeographic patterns. Coupled with this, there has been an increasing interdigitation of paleontology with molecular systematics because of the development of techniques to analyze ancient DNA and because of the use of sophisticated methods to utilize molecules to date evolutionary divergence events. One pervasive pattern emerging from several paleontological and molecular analyses of paleobiogeographic patterns is the recognition that repeated episodes of range expansion or geo-dispersal occur congruently in several different lineages, just as congruent patterns of vicariance also occur in independent lineages. The development of new analytical methods based on a modified version of Brooks Parsimony Analysis makes it possible to analyze both geo-dispersal and vicariance in a phylogenetic context, suggesting that biogeography as a discipline should focus on the analysis of a variety of congruent phenomena, not just vicariance. The important role that extinction plays in influencing apparent biogeographic patterns among modern and fossil groups suggests that this is another area ripe for new methodological developments.

\section{INTRODUCTION}

Biogeography is a dynamic discipline that has led to expansive growth in our understanding of the evolution and distribution of the Earth's biota. Not restricted to one research school or mode of thought, it is organized into two subdisciplines aimed at probing patterns in the genealogical and economic hierarchies: phylogenetic and ecological biogeography, respectively (Brooks \& McLennan 1991, 2002; Lieberman 2000, 2003a). The analysis of biogeographic patterns in fossil taxa, paleobiogeography, is also an important area of research (Hallam 1994, Lieberman 2000, Brooks \& McLennan 2002). There have been recent important gains and developments in paleobiogeography. These have occurred in three broad thematic areas. The first involves the appearance of new studies of fossil groups that incorporate a greater degree of analytical rigor; joined to this theme has been a growing unification of molecular evolution with paleontology, representing a rapprochement between these two fields. The second thematic area involves methodological 
developments generated specifically for the analysis of fossil data. Concomitant with these methodological developments, paleobiogeographers recognized that range expansion can occur congruently in several different groups and can be studied in a phylogenetic context. The final thematic area is associated with the recognition that extinction has left an indelible stamp on the modern biota, potentially challenging our ability to retrieve biogeographic patterns among organisms. The developments in each of these thematic areas suggests the need for a deeper consideration of the fossil record and its relevance to biogeography.

\section{IMPORTANT PALEOBIOGEOGRAPHIC STUDIES}

Most work in paleobiogeography has emphasized phylogenetic rather than ecological patterns. However, because ecological biogeography is such a rich discipline (e.g., Brown \& Maurer 1989, Rosenzweig 1995, Brown \& Lomolino 1998, Maurer 1999), it is anticipated that ecological paleobiogeographic studies are likely to represent an area of future growth for the field (Lieberman 2000). Still, the contributions of phylogenetic paleobiogeographic studies have been substantial.

\section{Early Contributions}

Fossils have long been an important factor in our understanding of the distribution of ancient continents and to the recognition that the Earth's plates have been in continuous motion (Hallam 1967, 1981). One of the real visionaries in this area is Tony Hallam (e.g., Hallam 1977, 1983, 1994). Paleobiogeographic studies have also demonstrated that some modern continents are built up of a melange of different terranes (Ross \& Ross 1985, Hallam 1986). One example is North America, which appears stable and unitary but in fact has a mixture of different terranes along its western margin. Many of these different terranes may have originally contained different biotas that traveled great distances (Hallam 1986, Ward et al. 1997). Thus, it is conceivable that some elements of the modern terrestrial biota of North America may represent forms that arrived rafted on terranes. However, thus far, biogeographic patterns from such groups as modern land snails (e.g., Scott 1997) suggest this may not be the case.

\section{Phylogenetic Approaches}

Building on these early contributions, paleobiogeography has in the past decade entered a phase where the underlying data and framework are explicitly phylogenetic, and the analytical methods used rely on phylogenetic approaches to biogeography. Diverse studies indicate the existence of one fundamental pattern: an oscillation between episodes of vicariance and episodes of range expansion throughout the history of life. Some of the most important paleobiogeographic studies have focused on dinosaurs. For instance, Sereno et al. (1996) documented biogeographic patterns in the largest, most awesome terrestrial predators to have stalked the earth: 
The patterns showed oscillating cycles of vicariance (in the Early Jurassic), followed by range expansion (in the Early Cretaceous), followed by vicariance (in the Late Cretaceous). Other well-known dinosaurs, such as the ceratopsians, have similar patterns (Sereno 1997). The early episodes of vicariance are associated with the breakup of Pangea during the Jurassic, and some of the strongest evidence for this comes from the vicariant links between dinosaurian (and also mammalian) faunas of Africa, South America, and Madagascar (Krause et al. 1997, Sampson et al. 1998).

Although the patterns of vicariance are important, they are not as prominent as the congruent range expansions (Sereno 1999). Although some (e.g., Upchurch et al. 2002) have argued for the dominant role of vicariance in dinosaur paleobiogeography, there are significant concerns about the quality and quantity of the data they utilized (Sereno 1997). The recognition of congruent, temporally correlated range expansion in independent clades matches the phenomenon of geo-dispersal identified by Lieberman \& Eldredge (1996) and Lieberman (1997, 2000). Lieberman \& Eldredge (1996) coined the term geo-dispersal to distinguish it from traditional dispersal [sensu (Humphries \& Parenti 1986)] that involves individual species moving over geographic barriers. Such traditional dispersal is by its very nature incongruent and not replicated in independent clades. The episodes of congruent range expansion or geo-dispersal appear to have been associated with large-scale plate tectonic events, such as continent-continent collisions, which facilitate concurrent range expansion by species in many independent clades because they eliminate geographic barriers. Wholesale climatic changes can also effectively do the same thing.

Analyses of such groups of fossil vertebrates as the mammals reiterate the pattern recovered from dinosaurs: Again, the mammals show evidence of congruent episodes of vicariance, followed by geo-dispersal, followed by vicariance. One of the pioneers in this area was McKenna $(1975,1983)$, who recognized that lineages in several independent clades of mammals moved between Europe and North America and between North America and Asia throughout the Cenozoic. Beard (1998) identified three consecutive waves in the Late Paleocene and Early Eocene from Asia into North America, involving the movement of primates, rodents, perissodactyls, artiodactyls, and other groups. It appears that climate changes, especially warming events, rather than tectonic events per se (which may have been the predominant factors for the earlier dinosaurs) caused these geo-dispersal events (Beard 1998, 2002; Bowen et al. 2002). Analysis of modern groups provides more evidence for repeated episodes of vicariance and geo-dispersal involving the biotas of North America, Asia, and Europe (Sanmartin et al. 2001).

Murray (2001), working with cichlid fishes, provides another intriguing study of vertebrate paleobiogeography that used a phylogenetic approach. By augmenting modern distributions of cichlids with those of fossil taxa, and mapping these distributions parsimoniously onto a phylogeny, she found evidence of numerous episodes of Cenozoic range expansion (Figure 1). This result is supported by the molecular clock studies of Vences et al. (2001). 


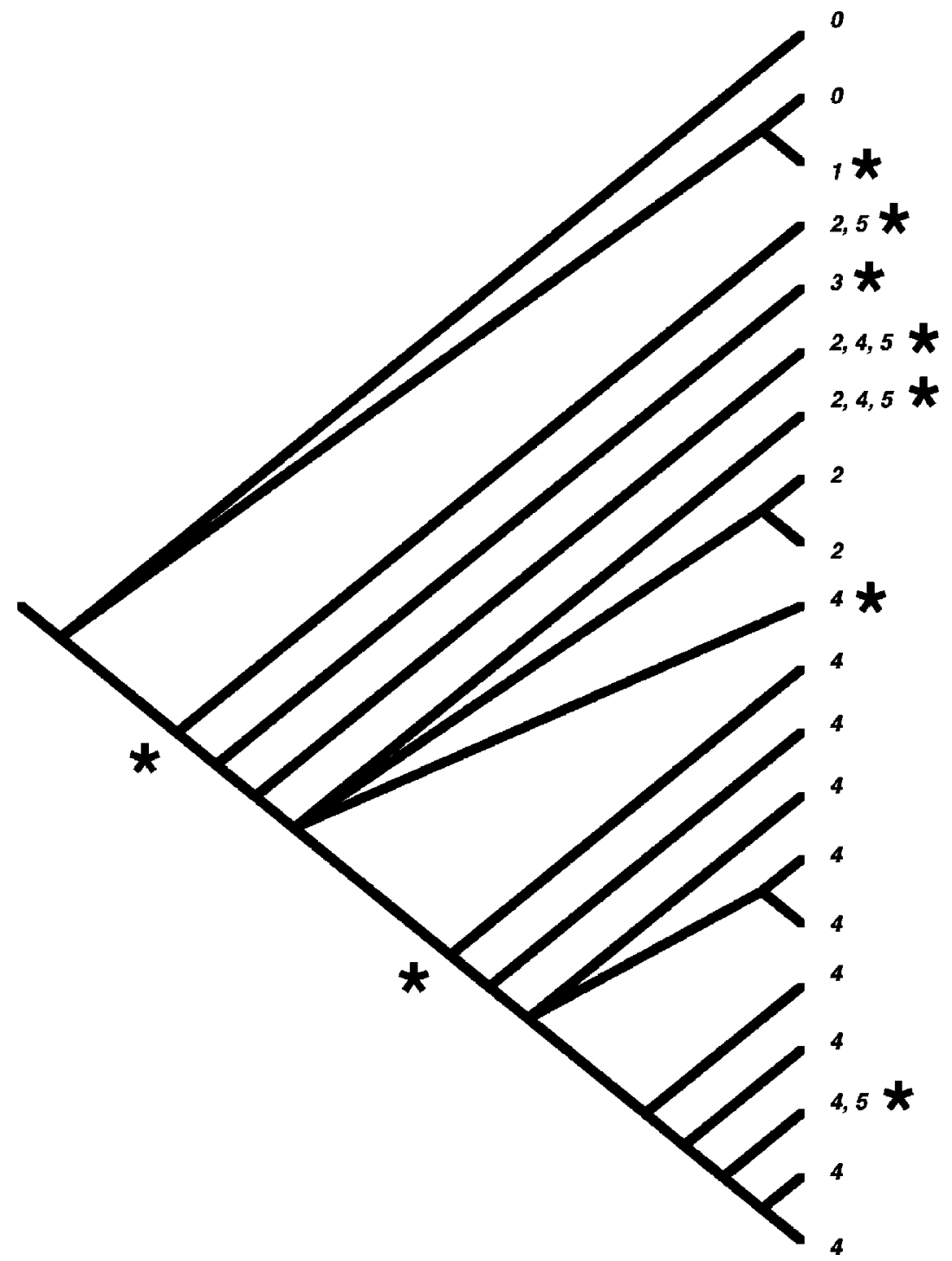

Figure 1 Paleobiogeographic patterns in extant and fossil cichlid fishes. The area of occurrence is substituted for the taxon name, with the area cladogram modified from Murray (2001), where $0=$ Madagascar; $1=$ India; $2=$ West Africa; $3=$ North America and South America; $4=$ East Africa; and $5=$ North Africa, Europe, and the Middle East. Mapping the geographic states to the ancestral nodes using phases one and two of Fitch (1971) optimization suggests that there were several range expansion events (each denoted by ${ }^{*}$ ) during the evolutionary history of the group. 
Phylogenetic approaches to paleobiogeography have not only focused on the charismatic vertebrates. Several important studies have examined paleobiogeographic patterns of fossil arthropods. Grimaldi (1992) used insect fossils to test hypotheses of vicariance. Hasiotis (1999) considered how the breakup of Pangea influenced paleobiogeographic patterns of fossil freshwater crayfish. Rode \& Lieberman (2002) evaluated the paleobiogeography of Devonian crustaceans and found evidence for vicariance and range expansion related to tectonic collision and sea-level rise and fall.

Phylogenetic paleobiogeographic analyses of the diverse marine invertebrate trilobites have also revealed important insights. An early study of these was conducted by Fortey \& Cocks (1992). Although they lacked detailed trilobite phylogenies to consider paleobiogeographic patterns, their study used a parsimony analysis of endemism (PAE). (See Bisconti et al. 2001 for an innovative application of PAE to modern organisms.) Ebach \& Edgecombe (2001) used trilobites to evaluate paleobiogeographic patterns while considering different analytical methods. Lieberman \& Eldredge (1996) applied a modified version of Brooks Parsimony Analysis (BPA), a method that is described in greater detail below, to five clades of Devonian trilobites. They recognized significant evidence of congruent episodes of vicariance and geo-dispersal. Patterns of vicariance and patterns of geo-dispersal can be expressed as trees that show, respectively, the relative times that geographic barriers formed, separating regions and encouraging vicariance, and fell, joining regions and encouraging geo-dispersal (Figure 2). The two trees are actually fairly similar for Devonian trilobites, suggesting that the processes controlling vicariance also governed geo-dispersal. This implicates repeated cycles of sea-level rise and fall as the arbiter of trilobite paleobiogeographic patterns. These cycles occurred extensively during the Devonian. Moreover, the Middle Devonian was a time of extensive continental collision, with the world's cratons approaching a Pangea-like configuration (Scotese 1997).

Using a similar approach, Lieberman (2002a; 2003b,c) conducted a phylogenetic paleobiogeographic analysis of Early Cambrian trilobites. Again, as with the Middle Devonian, the vicariance tree was well resolved, suggesting an important earth history control of evolution, with the formation of geographic barriers owing to tectonic rifting and sea-level fall leading to speciation. However, unlike in the Middle Devonian, the Early Cambrian geo-dispersal tree is relatively poorly resolved (Figure 3). This makes sense, as the Early Cambrian was a time when the Earth's continents were splitting apart (Torsvik et al. 1996, Dalziel 1997). The excessive vicariance in the Early Cambrian may have elevated speciation rates during the Cambrian radiation (Lieberman 1997), a time of rapid evolution when abundant skeletonized animals first appeared in the fossil record. By contrast, in the Devonian, rates of speciation of trilobites (and other groups) were more muted, possibly owing to the pervasive opportunities for range expansion at that time. The fact that clades of trilobites from both time periods reveal abundant evidence of paleobiogeographic congruence suggests that such Earth history events as tectonic and climatic changes exercise a fundamental control on evolution. Furthermore, 


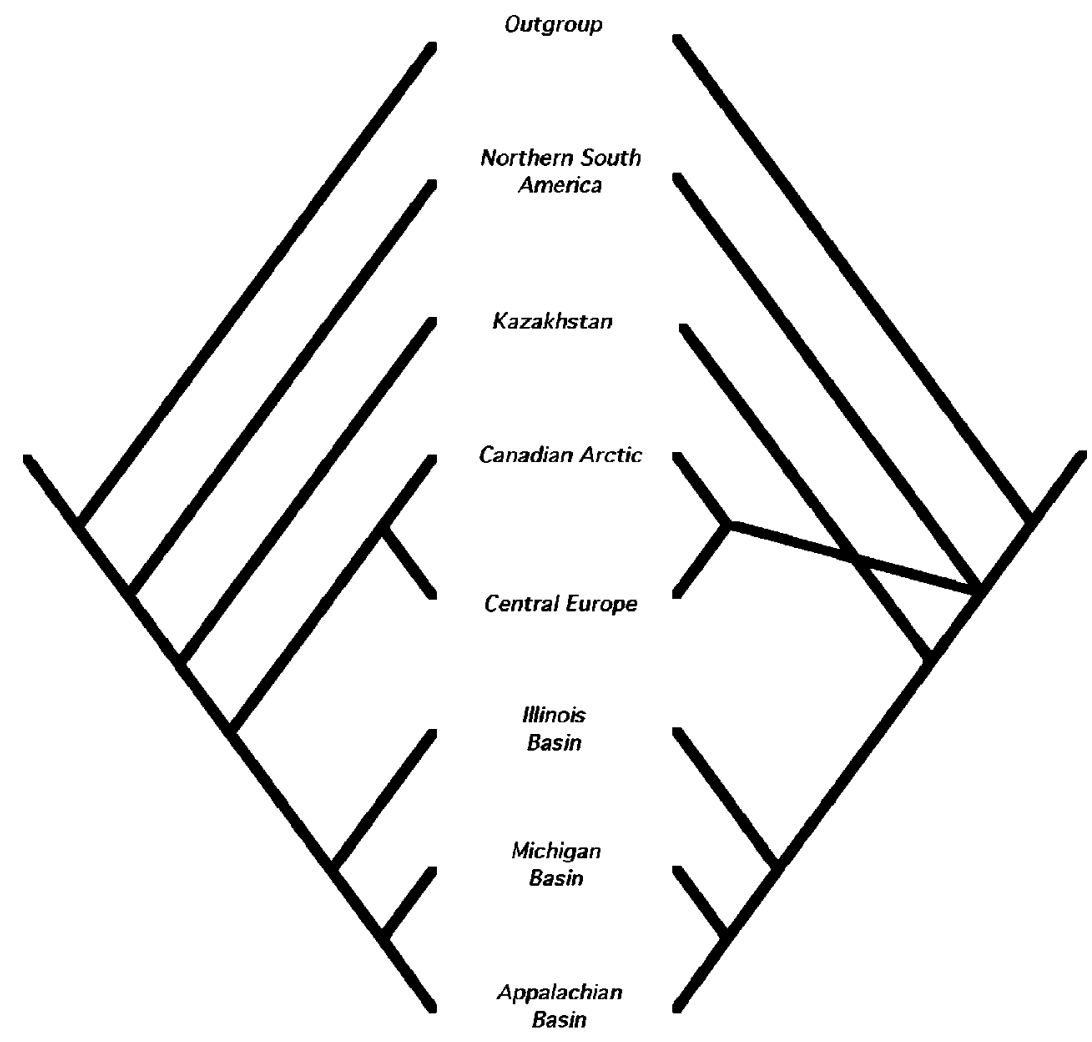

VICARIANCE

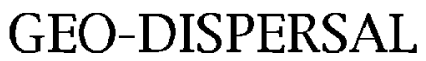

Figure 2 Paleobiogeographic patterns in Devonian trilobites based on Lieberman (2000), derived using the modified version of BPA described in the text. The most parsimonious pattern of vicariance and the strict consensus of the most parsimonious patterns of geo-dispersal are labeled. Also see discussion in Brooks \& McLennan (2002).

during times when the geological or climatic signatures differ, the corresponding evolutionary and paleobiogeographic signatures also differ.

Another important paleobiogeographic study is Waggoner's (1999) analysis of ediacarans. These are an enigmatic set of organisms that are most abundant in the Late Neoproterozoic, immediately prior to the Cambrian radiation. It is a matter of debate whether they represent a new kingdom of organisms, mostly modern phyla, or a combination of extinct and modern forms. Thus far recalcitrant to phylogenetic analysis because of their unusual anatomies, they cannot be subjected to phylogenetic paleobiogeographic analysis, so Waggoner (1999) analyzed paleobiogeographic patterns using PAE. The analysis revealed important 


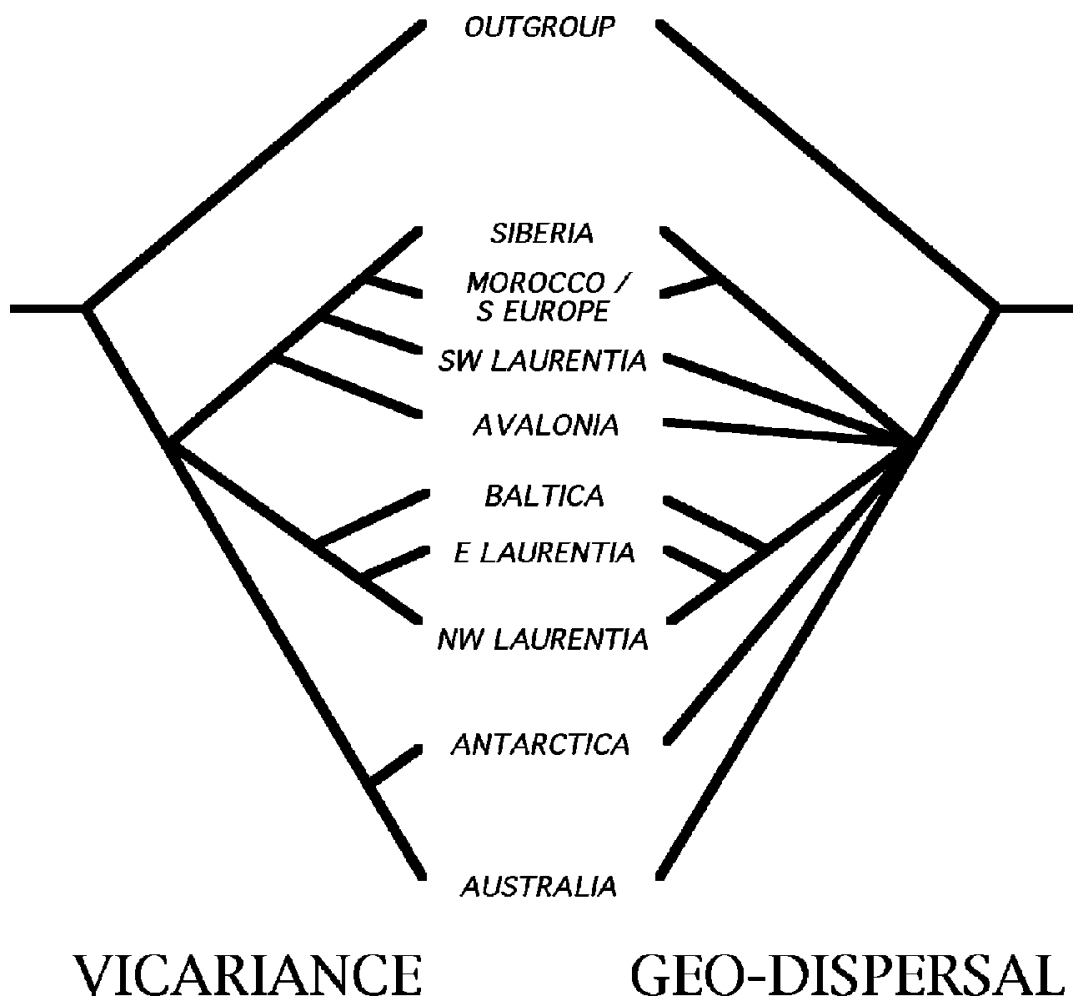

Figure 3 Paleobiogeographic patterns in Cambrian trilobites based on Lieberman (2003b,c), derived using the modified version of BPA described in the text. The most parsimonious pattern of vicariance and the strict consensus of the most parsimonious patterns of geo-dispersal are labeled. Laurentia refers to North America and Greenland, which were once conjoined; Baltica was a separate continent in the Cambrian, comprising Scandinavia and the eastern European platform; Avalonia refers to what was, in the Cambrian, a series of closely associated microcontinents including principally the eastern part of Newfoundland and much of Great Britain.

information about the breakup sequence of the supercontinent Rodinia, an early analog of the supercontinent Pangea but with the continents in different positions, which began to split apart shortly before the Cambrian radiation.

\section{Paleomolecular Analyses}

Understanding biogeographic patterns connecting extinct and modern lineages remains a major challenge (Lieberman 2000, 2002b; Murphy et al. 2001), yet important progress has been made. In particular, the analysis of ancient DNA and the refinement of approaches for dating divergence events using molecules enabled 
several new approaches to paleobiogeography. In a sense, such techniques have expanded the purview of paleobiogeography and biogeography and allowed more interdigitation between the two fields. Austin \& Arnold (2001), using molecular phylogenetics of ancient DNA, analyzed biogeographic patterns in extinct land tortoises from the Mascarene Islands, an island chain that lies east of Malagasy. They found evidence for episodes of colonization from Mauritius to other islands in the island chain (Figure 4). Haddrath \& Baker (2001), in an exciting study, merged the analysis of paleobiogeographic and biogeographic patterns through analysis of complete mtDNA genomes of two extinct large flightless birds (moas)

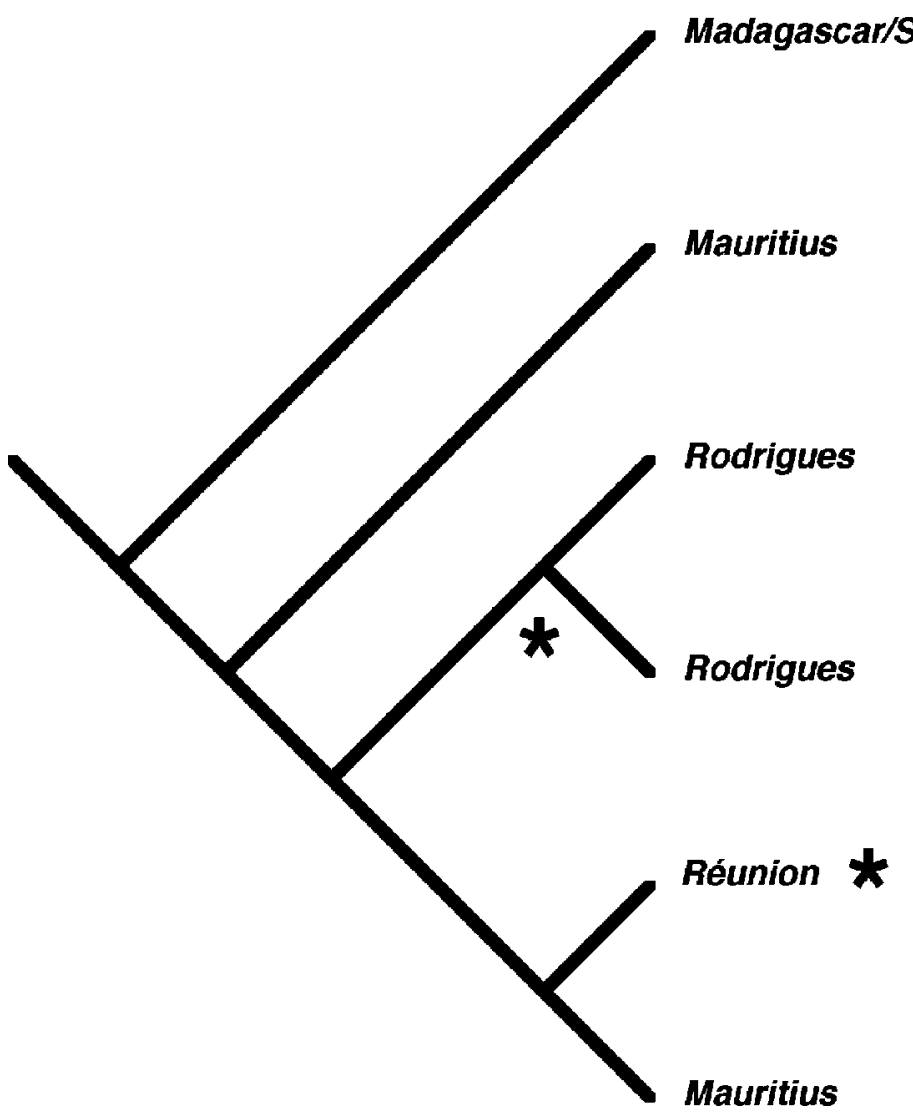

Figure 4 Paleobiogeographic patterns in the extinct land tortoise Cylindraspis. The area of occurrence is substituted for the species name, and the area cladogram is modified from Austin \& Arnold (2001). Mapping the geographic states to the ancestral nodes using phases one and two of Fitch (1971) optimization suggests that there were two range expansion events (each denoted by ${ }^{*}$ ) during the evolutionary history of the group. 
from New Zealand. Their molecular systematic study of large flightless ratite birds included five extant taxa along with the two extinct species. They used molecular sequence data to reconstruct evolutionary relationships and time divergence events. Haddrath \& Baker (2001) found that some of the divergence events in the ratites were likely episodes of vicariance driven by the fragmentation of Gondwana, as Cracraft (2001) has posited; however, other episodes of secondary range expansion into New Zealand were also indicated. A similar pattern was recovered in the flying passerines by Ericson et al. (2002), providing support for the idea that different groups that occur together evolve congruently across geographic space in spite of differences in dispersal abilities.

Of course ancient DNA can be isolated only rarely. Molecular studies, however, need not be constrained by their inability to incorporate extinct taxa, and such studies can still make important contributions to our understanding of paleobiogeography. One such instance is revealed in the work of Murphy et al. (2001). They used Bayesian and maximum likelihood methods to look at the interordinal relationships of mammals. They found evidence for a basal split in the group that appears to be related to the split of South America and Africa 100 Mya, thereby correlating this key evolutionary event with a major geological event.

In another interesting study, Conti et al. (2002) used molecular systematics and molecular dating techniques to show how the Indian plate, during its independent history in the Cretaceous and Cenozoic, picked up a plant lineage in Africa and deposited it in Asia, an excellent example of geo-dispersal.

Even the lowly cockroach, a lineage well adapted to modern urban environments, shows the stamp of major episodes of geological and climatic change in its evolutionary history (Clark et al. 2001). Because of the relatively limited fossil record of this group, insight into the timing of biogeographic and paleobiogeographic patterns can be afforded only by analysis of degrees of molecular divergence.

These molecular analyses are in many ways complementary to paleobiogeographic studies that rely on information from organismal phylogenies and distribution gleaned from fossils. One area, however, where paleobiogeographic analysis of fossils is handicapped is in the analysis of patterns of intraspecific differentiation, which is difficult to analyze using a phylogenetic approach in fossil organisms. Such patterns are, however, particularly important if we seek to understand the biogeographic and evolutionary effects of the more recent major climatic changes that have occurred in the past few million years. One important area in which the field of biogeography has expanded in recent years, as documented by Brooks \& McLennan (2002), is in the development of molecular phylogeography. This is a vibrant research area pioneered by Avise (1992), Zink (1996), and others. Even though the focus of phylogeography is on the differentiation of populations within species rather than species within clades, as is typically the case with paleobiogeography, it is remarkable how on the whole phylogeographic patterns conform well with paleobiogeographic patterns in one particular respect: Both show evidence for repeated episodes of vicariance and range expansion (geo-dispersal) 
occurring in an oscillatory fashion, albeit operating at different hierarchical levels and different timescales. For example, Lieberman (2001) found molecular phylogeographic evidence for repeated episodes of vicariance and geo-dispersal in a freshwater bivalve distributed in the central United States, a region buffeted by major climatic changes in the past two million years. This mollusc appears to have responded to the profound climatic changes by tracking habitat, rather than by speciating. The same result is reiterated in disparate groups including fish (Wiley \& Mayden 1985) and birds (Klicka \& Zink 1997), and it also emerged upon analysis of a broad swath of the flora and fauna in Europe that responded to a similar scope of climatic changes (Taberlet et al. 1998).

\section{METHODOLOGICAL DEVELOPMENTSIN PALEOBIOGEOGRAPHY}

Evidence seems to be accumulating from paleobiogeographic studies (including the studies already emphasized) that the history of clades and biotas involves cycles of vicariance and geo-dispersal. Indeed, the recognition that cycles of congruent range expansion and vicariance have oscillated repeatedly has a long historical heritage extending back to Lyell (1832), the Darwinian notebooks of 1837-1838 (in Barrett et al. 1987), Huxley (1870), and Wallace (1876) (see review in Lieberman 2000). More recently, several authors that operate within an explicitly phylogenetic perspective have recognized the existence of a similar pattern (e.g., Brundin 1988; Cracraft 1988; Noonan 1988; Wiley 1988a; Bremer 1992; Ronquist 1994, 1998; Lieberman \& Eldredge 1996; Riddle 1996; Hovenkamp 1997; Lieberman 1997, 2000; Voelker 1999; Waggoner 1999; Bisconti et al. 2001; Brooks \& McLennan 2002).

The existence of congruent patterns of geo-dispersal indicates that it would be beneficial to have a biogeographic method designed to retrieve both vicariance and geo-dispersal. Fortunately, such a method has been developed recently expressly for the analysis of paleobiogeographic data, although it can just as readily be used for analysis of biogeographic patterns in extant taxa (Lieberman \& Eldredge 1996; Lieberman 1997, 2000). In an important sense, this method is based on the recognition that phylogenetic biogeography and paleobiogeography must be about the study of evolutionary and geographic congruence, not just vicariance. Instead of limiting phylogenetic biogeography simply to the analysis of one type of congruent biogeographic pattern, vicariance, scientists should welcome the opportunity to identify and study other types of Earth history events also related to plate tectonics or climate change that can congruently influence evolution and geographic distribution. Further, if geo-dispersal is ignored and biogeographic data analyzed using only a vicariance approach, results may be difficult to interpret, appear unresolved, or be simply inaccurate because of the overlapping signature of two different types of biogeographic processes.

The method for using phylogenetic information in conjunction with distributional data to identify geo-dispersal side by side with vicariance is based on a 
modified version of BPA. BPA was described in detail by Brooks (1981, 1985, 1990), Wiley (1988a,b), Funk \& Brooks (1990), Wiley et al. (1991), and Brooks \& McLennan (1991, 2002). The modified version of BPA is methodologically and philosophically similar to standard BPA but differs in a few key details. The method starts with an area cladogram: a phylogeny with the geographic distributions substituted for the taxon names. Then, the geographic states are optimized onto the nodes of the tree using phases one and two of the Fitch (1971) parsimony algorithm, which allows unordered transformation between character states (see discussion in Lieberman 2000). The area cladogram is subsequently converted into two separate data matrices: one designed to retrieve congruent episodes of vicariance and one designed to retrieve congruent episodes of geo-dispersal. Each data matrix has the areas of interest and an all-zero (absent) outgroup to polarize biogeographic character change.

The characters of the matrices code the nodes and the terminals of the tree along with the biogeographic transitions between ancestral and descendant nodes and ancestral nodes and descendant terminals. The manner in which the transitions are coded differs in the two data matrices. For instance, transitions between ancestral nodes and descendant nodes or terminals that involve range contraction are treated as putative episodes of vicariance and coded as an ordered multistate character in the vicariance matrix but not in the geo-dispersal matrix. By contrast, transitions between ancestral nodes and descendant nodes or terminals that involve range shifts or expansions are treated as putative episodes of geo-dispersal and coded as an ordered multistate character in the geo-dispersal matrix but not in the vicariance matrix (Lieberman \& Eldredge 1996; Lieberman 1997, 2000) (see Figure 5 and Tables 1 and 2). After all area cladograms are coded into the two data matrices, each matrix is analyzed separately using the parsimony algorithm PAUP (Swofford 1998).

Repeated patterns of vicariance involving the same areas are treated as support for a particular area history in the vicariance tree. Patterns of range expansion do not figure into the construction of this tree and do not create homoplasy. By contrast, repeated patterns of geo-dispersal involving the same areas are treated as support for a particular area history in the geo-dispersal tree, and patterns of vicariance do not figure into the construction of this tree and do not create homoplasy. If there is limited evidence for vicariance or geo-dispersal in either matrix, the resultant tree(s) will be poorly resolved or only weakly supported.

The results are expressed as two most parsimonious trees, the vicariance and geo-dispersal trees, depicting patterns of the common history of areas and biotas. The vicariance tree gives information about the relative times that geographic barriers formed separating regions: The closer two areas are on the tree the more recently they shared a common history and the more recently barriers formed between them. The geo-dispersal tree gives information about the relative time that geographic barriers fell, joining regions: The closer two areas are on the tree the more recently barriers fell, joining regions.

In some instances the geo-dispersal trees and the vicariance trees are both well resolved, such as the example from Lieberman \& Eldredge (1996) discussed above. By contrast, in examples involving different time periods, such as 


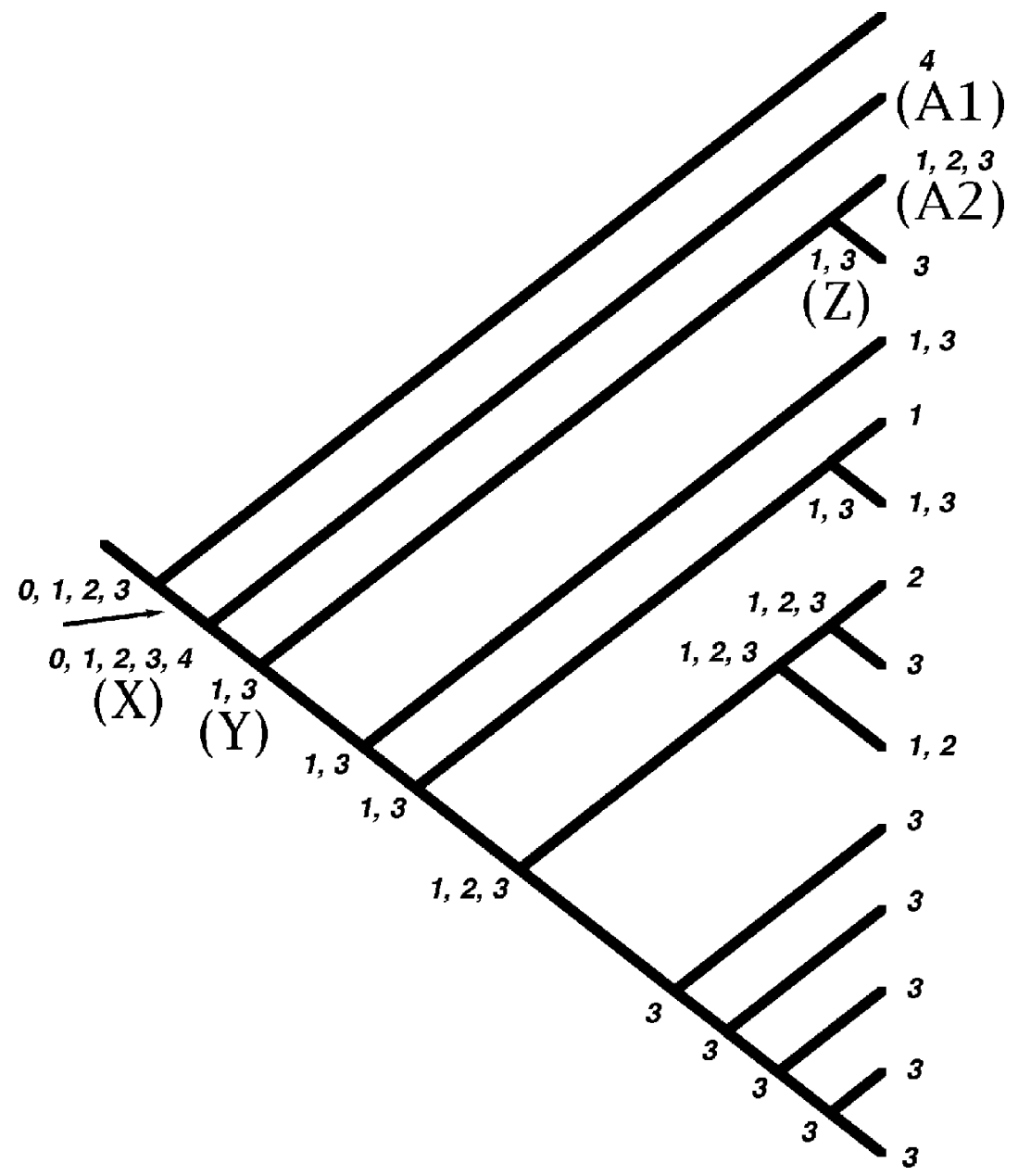

Figure 5 Area cladogram, with biogeographic states depicted as numbers, to illustrate the mechanics of the modified version of BPA described herein. These states were mapped to the ancestral nodes using phases one and two of Fitch (1971) optimization. The ancestral biogeographic state of the clade is indicated by the arrow. The letters next to the nodes and terminals are used in Tables 1 and 2. Figure based on Lieberman (2000).

Lieberman's (1997, 2003b,c) studies of the Early Cambrian described above, only the vicariance tree is well resolved. Although this method has thus far only been applied to the analysis of paleobiogeographic data, it can be applied to extant taxa without modification.

Ronquist (1997) developed dispersal-vicariance analysis, which is another attempt to consider episodes of range expansion within a phylogenetic framework. The method uses a model to consider the prevalence of different modes of 
TABLE 1 Modified BPA coding of five characters of the vicariance matrix representing, in order, the basal node, node $\mathrm{X}$, terminal taxon $\mathrm{A} 1$, nodes $\mathrm{Y}$ and $\mathrm{Z}$, and terminal taxon $\mathrm{A} 2$, all from the area cladogram in Figure 5

\begin{tabular}{lllllll}
\hline & \multicolumn{7}{c}{ Characters } \\
\cline { 2 - 6 } Taxon & $\mathbf{1}$ & $\mathbf{2}$ & $\mathbf{3}$ & $\mathbf{4}$ & $\mathbf{5}$ & $\mathbf{6}$ \\
\hline Outgroup & 0 & 0 & 0 & 0 & 0 & 0 \\
Area 0 & 1 & 1 & 1 & 1 & 0 & 0 \\
Area 1 & 1 & 1 & 1 & 2 & 1 & 1 \\
Area 2 & 1 & 1 & 1 & 1 & 0 & 1 \\
Area 3 & 1 & 1 & 1 & 2 & 1 & 1 \\
Area 4 & 0 & 1 & 2 & 1 & 0 & 0 \\
\hline
\end{tabular}

0 indicates absent from a region; 1 and 2 indicate present in a region; outgroup refers to the ancestral biogeographic condition for the clade; multistate characters are ordered.

speciation in evolution and was recently implemented in a study by Zink et al. (2000). Although the method cannot be used to synthesize biogeographic patterns from different groups and does not distinguish traditional dispersal from geodispersal, unlike Lieberman \& Eldredge's (1996) and Lieberman's (1997, 2000) method, it demonstrates the growing interest that phylogenetic biogeographers have in looking beyond vicariance as the sole process producing significant biogeographic patterns.

TABLE 2 Modified BPA coding of five characters of the geo-dispersal matrix representing, in order, the basal node, node $\mathrm{X}$, terminal taxon $\mathrm{A} 1$, nodes $\mathrm{Y}$ and $\mathrm{Z}$, and terminal taxon $\mathrm{A} 2$, all from the area cladogram in Figure 5

\begin{tabular}{lllllll}
\hline & \multicolumn{7}{c}{ Characters } \\
\cline { 2 - 7 } Taxon & $\mathbf{1}$ & $\mathbf{2}$ & $\mathbf{3}$ & $\mathbf{4}$ & $\mathbf{5}$ & $\mathbf{6}$ \\
\hline Outgroup & 0 & 0 & 0 & 0 & 0 & 0 \\
Area 0 & 1 & 1 & 0 & 0 & 0 & 0 \\
Area 1 & 1 & 1 & 0 & 1 & 1 & 1 \\
Area 2 & 1 & 1 & 0 & 0 & 0 & 2 \\
Area 3 & 1 & 1 & 0 & 1 & 1 & 1 \\
Area 4 & 0 & 2 & 1 & 0 & 0 & 0 \\
\hline
\end{tabular}

0 indicates absent from a region; 1 and 2 indicate present in a region; outgroup refers to the ancestral biogeographic condition for the clade; multistate characters are ordered. 


\section{THE EFFECTS OF EXTINCTION ON THE ANALYSIS OF PALEOBIOGEOGRAPHIC AND BIOGEOGRAPHIC PATTERNS}

Extinction has the potential to obscure or bias paleobiogeographic patterns because through time the biotas of regions may appear different simply because one region has experienced differential extinction. For example, Sereno (1999) argued that this phenomenon underlies the apparent increase in endemism seen in some dinosaur faunas through time. Also, Van Oosterzee (1997) argued that extinction of island biotas precipitated by volcanic cataclysms underlies some modern biotic disparities in the Malay Archipelago. She suggested that eruption amplified apparent degrees of endemism by wholesale elimination of various taxa that were biotic intermediates.

Extinction can also complicate biogeographic studies of the extant biota (Lieberman 2000, 2002b). This is due to a situation analogous to one recognized by Gauthier et al. (1988) and Donoghue et al. (1989) for phylogenetic analyses of extant organisms. These may produce incorrect topologies because critical extinct taxa are excluded. Lieberman (2002b) suggested, based on simulation studies, that extant clades may appear biogeographically incongruent artificially, simply owing to accumulated extinction. Such artificial incongruence is especially prevalent in long-lived clades or in clades with high extinction probabilities; this may mean that at times it will be difficult to reconstruct the stamp of temporally distant tectonic events on the modern biota.

In essence, Wiley \& Mayden (1985) and Brooks \& McLennan (1991) identified this same phenomenon when they recognized that only geologically young clades that had not accumulated too much extinction should be the subjects of phylogenetic biogeographic analyses. Paleobiogeographers need not be as concerned with this second type of effect of extinction, as generally all of their subjects are extinct. However, they must be concerned with the quality of the fossil record. The incompleteness of the fossil record biases the preservation of fossil taxa and thus operates in a manner analogous to the effects extinction has on the extant biota (Lieberman 2002b). Fossil groups or time periods with poor fossil records also make the analysis of paleobiogeographic patterns problematic because a poor fossil record can also create artificial incongruence (Lieberman 2002b).

Because both biogeographic and paleobiogeographic studies may have a predilection toward artificial incongruence, potentially ideal biogeographic studies would be those that incorporate both fossil and extant taxa. This is not possible in some groups of organisms. Still, even in these groups, consideration of the fossil record may be helpful, for this is the place to turn to identify the ages of clades or other parameters such as the extinction probabilities of lineages within these clades. This information could in turn be used in simulation studies to evolve hypothetical clades comparable to a clade of interest to estimate to what extent the apparent biogeographic patterns in the modern clade may have been distorted by artificial biogeographic incongruence. These and other considerations represent a compelling argument for a theoretical unification of biogeography with 
paleobiogeography (also see Brooks \& McLennan 1991, 2002). It is clear that the analysis of how extinction affects our ability to retrieve biogeographic patterns is still in its early stages, but this is likely to be an area of future important insights (Lieberman 2000, 2002b).

\section{CONCLUSIONS}

Paleobiogeography is a discipline that has recently shown renewed growth. This partly reflects an increasing emphasis on taking phylogenetic approaches to the study of paleobiogeography. It also results from an expansion of the scope of the field, which now includes studies of ancient DNA and studies that incorporate molecular methods to date biogeographic events. Paleobiogeographic analyses have spurred the recognition that vicariance is not the only process capable of producing biogeographic congruence. Geo-dispersal of organisms related to the fall of geographic barriers, driven by tectonism or climate change, can also structure geographic distributions in independent clades simultaneously. This is a very different process from traditional dispersal, which involves movement over a barrier that is unlikely to occur congruently in different lineages. Concomitant with the recognition of the potential significance of geo-dispersal, methodological advances in paleobiogeographic analysis have also occurred, including modifications of such well-known techniques as BPA to allow geo-dispersal to be treated within an analytical framework. Finally, insights from paleobiogeography suggest that extinction is a process that may influence our ability to retrieve biogeographic patterns in extant organisms, and thus extinct fossil taxa should be considered in biogeographic analysis whenever possible. All of these suggest that some excellent opportunities for conceptual and methodological advances may occur on the interface between paleobiogeography and biogeography.

\section{ACKNOWLEDGMENTS}

Thanks to Dan Brooks, Tony Hallam, Roger Kaesler, Alycia Rode, Paul Sereno, the scientific editor of this series, and Ed Wiley for helpful comments on earlier versions of this manuscript. This research was supported by NSF OPP-9909302; NSF EAR-0106885; and a Self Faculty Fellowship.

\section{The Annual Review of Ecology, Evolution, and Systematics is online at http://ecolsys.annualreviews.org}

\section{LITERATURE CITED}

Austin JJ, Arnold EN. 2001. Ancient mitochondrial DNA and morphology elucidate an extinct island radiation of Indian Ocean giant tortoises (Cylindraspis). Proc. R. Soc. London Ser. B 268:2515-23
Avise JC. 1992. Molecular population structure and the biogeographic history of a regional fauna: a case history with lessons for conservation biology. Oikos 63:62-76

Barrett PH, Gautrey PJ, Herbert S, Kohn D, 
Smith S. 1987. Charles Darwin's Notebooks, 1836-1844. Ithaca, NY: Cornell Univ. Press

Beard KC. 1998. East of Eden: Asia as an important center of taxonomic origination in mammalian evolution. Bull. Carnegie Mus. Nat. Hist. 34:5-39

Beard KC. 2002. East of Eden at the Paleocene/ Eocene boundary. Science 295:2028-29

Bisconti M, Landini W, Bianucci G, Cantalamessa G, Carnevale G, et al. 2001. Biogeographic relationships of the Galapagos terrestrial biota: parsimony analyses of endemicity based on reptiles, land bards and Scalesia land plants. J. Biogeogr. 28:495-510

Bowen GJ, Clyde WC, Koch PL, Ting S, Alroy $J$, et al. 2002. Mammalian dispersal at the Paleocene/Eocene boundary. Science 295:2062-65

Bremer K. 1992. Ancestral areas: a cladistic reinterpretation of the center of origin concept. Syst. Biol. 41:436-45

Brooks DR. 1981. Hennig's parasitological method: a proposed solution. Syst. Zool. 30:229-49

Brooks DR. 1985. Historical ecology: a new approach to studying the evolution of ecological associations. Ann. Mo. Bot. Gard. 72:660-80

Brooks DR. 1990. Parsimony analysis in historical biogeography and coevolution: methodological and theoretical update. Syst. Zool. 39:14-30

Brooks DR, McLennan DA. 1991. Phylogeny, Ecology, and Behavior. Chicago: Univ. Chicago Press

Brooks DR, McLennan DA. 2002. The Nature of Diversity. Chicago: Univ. Chicago Press

Brown JH, Lomolino MV. 1998. Biogeography. Sunderland, MA: Sinauer. 2nd ed.

Brown JH, Maurer BA. 1989. Macroecology: the division of food and space among species on continents. Science 243:1143-50

Brundin LZ. 1988. Phylogenetic biogeography. In Analytical Biogeography, ed. AA Myers, PS Giller, pp. 343-69. New York: Chapman \& Hall

Clark JW, Hossain S, Burnside CA, Kambhampati S. 2001. Coevolution between a cock- roach and its bacterial endosymbiont: a biogeographical perspective. Proc. R. Soc. London Ser. B 268:393-98

Conti E, Eriksson T, Schonenberger J, Systsma KJ, Baum DA. 2002. Early Tertiary out of India dispersal of Crypteroniaceaea: evidence from phylogeny and molecular dating. Evolution 56:1931-42

Cracraft J. 1988. Deep-history biogeography: retrieving the historical pattern of evolving continental biotas. Syst. Zool. 37:221-36

Cracraft J. 2001. Avian evolution, Gondwana biogeography and the Cretaceous-Tertiary mass extinction event. Proc. R. Soc. London Ser. B 268:459-69

Dalziel IWD. 1997. Neoproterozoic-Paleozoic geography and tectonics: review, hypothesis, and environmental speculations. Geol. Soc. Am. Bull. 109:16-42

Donoghue MJ, Doyle J, Gauthier J, Kluge A, Rowe T. 1989. The importance of fossils in phylogeny reconstruction. Annu. Rev. Ecol. Syst. 20:431-60

Ebach MC, Edgecombe GD. 2001. Cladistic biogeography: component-based methods and paleontological application. In Fossils, Phylogeny, and Form: An Analytical Approach, ed. JM Adrain, GD Edgecombe, BS Lieberman, pp. 235-89. New York: Kluwer Academic/Plenum

Ericson PGP, Christidis L, Cooper A, Irestedt M, Jackson J, et al. 2002. A gondwanan origin of passerine birds supported by DNA sequences of the endemic New Zealand wrens. Proc. R. Soc. London Ser. B 269:235-41

Fitch WM. 1971. Toward defining the course of evolution: minimum change for a specific tree topology. Syst. Zool. 20:406-16

Fortey RA, Cocks LRM. 1992. The early Paleozoic of the North Atlantic region as a test case for the use of fossils in continental reconstruction. Tectonophysics 206:147-58

Funk VA, Brooks DR. 1990. Phylogenetic systematics as the basis of comparative biology. Smithson. Contrib. Bot. 73:1-45

Gauthier J, Kluge AG, Rowe T. 1988. Amniote phylogeny and the importance of fossils. Cladistics 4:105-209 
Grimaldi DA. 1992. Vicariance biogeography, geographic extinctions, and the North American Oligocene Tsetse flies. In Extinction and Phylogeny, ed. MJ Novacek, QD Wheeler, pp. 184-204. New York: Columbia Univ. Press

Haddrath O, Baker AJ. 2001. Complete mitochondrial DNA genome sequences of extinct birds: ratite phylogenetics and the vicariance biogeography hypothesis. Proc. R. Soc. London Ser. B 268:939-45

Hallam A. 1967. The bearing of certain paleogeographic data on continental drift. Palaeogeogr. Palaeoclimatol. Palaeoecol. 3:201-24

Hallam A. 1977. Jurassic bivalve biogeography. Paleobiology 3:58-73

Hallam A. 1981. Great Geological Controversies. New York: Oxford Univ. Press

Hallam A. 1983. Early and mid-Jurassic molluscan biogeography and the establishment of the central Atlantic seaway. Palaeogeogr. Palaeoclimatol. Palaeoecol. 43:181-93

Hallam A. 1986. Evidence of displaced terranes from Permian to Jurassic faunas around the Pacific margins. J. Geol. Soc. London 143:209-16

Hallam A. 1994. An Outline Of Phanerozoic Biogeography, Vol. 10. Oxford: Oxford Univ. Press

Hasiotis ST. 1999. The origin and evolution of freshwater crayfish based on crayfish body and trace fossils. Freshw. Crayfish 12:49-70

Hovenkamp P. 1997. Vicariance events, not areas, should be used in biogeographical analysis. Cladistics 13:67-79

Humphries CJ, Parenti L. 1986. Cladistic biogeography. Oxford Mon. Biogeogr. 2:1-98

Huxley TH. 1870. Anniversary address. In The Scientific Memoirs of Thomas Henry Huxley, ed. M Foster, ER Lankester, pp. 510-50. London: Macmillan

Klicka J, Zink RM. 1997. The importance of recent Ice Ages in speciation: a failed paradigm. Science 277:1666-69

Krause DW, Prasad GVR, von Koenigswald W, Sahni A, Grine FE. 1997. Cosmopolitanism among gondwanan Late Cretaceous mammals. Nature 390:504-7
Lieberman BS. 1997. Early Cambrian paleogeography and tectonic history: a biogeographic approach. Geology 25:1039-42

Lieberman BS. 2000. Paleobiogeography. New York: Plenum/Kluwer Academic

Lieberman BS. 2001. Applying molecular phylogeography to test paleoecological hypotheses: a case study involving Amblema plicata (Mollusca: Unionidae). In Evolutionary Paleoecology, ed. WD Allmon, DJ Bottjer, pp. 83-103. New York: Columbia Univ. Press

Lieberman BS. 2002a. Phylogenetic analysis of some basal Early Cambrian trilobites, the biogeographic origins of the Eutrilobita, and the timing of the Cambrian radiation. $\mathrm{J}$. $\mathrm{Pa}$ leontol. 76:692-708

Lieberman BS. 2002b. Phylogenetic biogeography with and without the fossil record: gauging the effects of extinction and paleontological incompleteness. Palaeogeogr. Palaeoclimatol. Palaeoecol. 178:39-52

Lieberman BS. 2003a. Unifying theory and methodology in biogeography. Evol. Biol. 33:1-25

Lieberman BS. 2003b. Biogeography of the Cambrian radiation: deducing geological processes from trilobite evolution. Spec. Pap. Palaeontol. In press

Lieberman BS. 2003c. Taking the pulse of the Cambrian radiation. J. Int. Comp. Biol. 43(1):In press

Lieberman BS, Eldredge N. 1996. Trilobite biogeography in the Middle Devonian: geological processes and analytical methods. Paleobiology 22:66-79

Lyell C. 1832. Principles of Geology, Vol. 2. Chicago: Univ. Chicago Press. 2nd ed.

Maurer BA. 1999. Untangling Ecological Complexity. Chicago: Univ. Chicago Press

McKenna MC. 1975. Fossil mammals and Early Eocene North Atlantic land continuity. Ann. Mo. Bot. Gard. 62:335-53

McKenna MC. 1983. Holarctic landmass rearrangement, cosmic events, and Cenozoic terrestrial organisms. Ann. Mo. Bot. Gard. 70:459-89

Murphy WJ, Eizirik E, O’Brien SJ, Madsen 
O, Scally M, et al. 2001. Resolution of the early placental mammal radiation using Bayesian phylogenetics. Science 294:234851

Murray AM. 2001. The fossil record and biogeography of the Cichlidae (Actinopterygii: Labroidei). Biol. J. Linn. Soc. 74:51732

Noonan GR. 1988. Biogeography of North American and Mexican insects, and a critique of vicariance biogeography. Syst. Zool. 37:366-84

Riddle BR. 1996. The molecular phylogeographic bridge between deep and shallow history in continental biotas. Trends Ecol. Evol. 11:207-11

Rode A, Lieberman BS. 2002. Phylogenetic and biogeographic analysis of Devonian phyllocarid crustaceans. J. Paleontol. 76:27186

Ronquist F. 1994. Ancestral areas and parsimony. Syst. Biol. 43:267-74

Ronquist F. 1997. Dispersal-vicariance analysis: a new approach to the quantification of historical biogeography. Syst. Biol. 46:195203

Ronquist F. 1998. Phylogenetic approaches in coevolution and biogeography. Zool. Scr. 26:313-22

Rosenzweig ML. 1995. Species Diversity in Space and Time. New York: Cambridge Univ. Press

Ross A, Ross JRP. 1985. Carboniferous and early Permian biogeography. Geology 13:27-30

Sampson SD, Witmer LM, Forster CA, Krasue DW, O'Connor PM, et al. 1998. Predatory dinosaur remains from Madagascar: implications for the Cretaceous biogeography of Gondwana. Science 280:1048-51

Sanmartin I, Enghoff H, Ronquist F. 2001. Patterns of animal dispersal, vicariance and diversification in the Holarctic. Biol. J. Linn. Soc. 73:345-90

Scotese CR. 1997. Paleogeographic Atlas. Arlington, TX: Paleomap Proj.

Scott B. 1997. Biogeography of the Helicoidea (Mollusca: Gastropoda: Pulmonata): land snails with a Pangean distribution. J. Biogeogr. 24:399-407

Sereno PC. 1997. The origin and evolution of dinosaurs. Annu. Rev. Earth Planet. Sci 25:435-89

Sereno PC. 1999. The evolution of dinosaurs. Science 284:2137-47

Sereno PC, Dutheil DB, Iarochene M, Larsson HCE, Lyon GH, et al. 1996. Predatory dinosaurs from the Sahara and Late Cretaceous faunal differentiation. Science 272:98691

Swofford DL. 1998. PAUP (Phylogenetic Analysis Using Parsimony), Version 4.0. Sunderland, MA: Sinauer

Taberlet P, Fumagalli L, Wust-Saucy A-G, Cosson J-F. 1998. Comparative phylogeography and postglacial colonization routes in $\mathrm{Eu}-$ rope. Mol. Ecol. 7:453-64

Torsvik TH, Smethurst MA, Meert JG, Van der Voo R, McKerrow WS, et al. 1996. Continental breakup and collision in the Neoproterozoic and Paleozoic - a tale of Baltica and Laurentia. Earth Sci. Rev. 40:229-58

Upchurch P, Hunn CA, Norman DB. 2002. An analysis of dinosaurian biogeography: evidence for the existence of vicariance and dispersal patterns caused by geological patterns. Proc. R. Soc. London Ser. B 269:61321

Van Oosterzee P. 1997. Where Worlds Collide. Ithaca, New York: Cornell Univ. Press

Vences M, Freyhoff J, Sonnenberg R, Kosuch J, Veith M. 2001. Reconciling fossils and molecules: Cenozoic divergence of cichlid fishes and the biogeography of Madagascar. J. Biogeogr. 28:1091-99

Voelker G. 1999. Dispersal, vicariance, and clocks: historical biogeography and speciation in a cosmopolitan passerine genus (Anthus: Motacillidae). Evolution 53:153652

Waggoner B. 1999. Biogeographic analyses of the Ediacara biota: a conflict with paleotectonic reconstructions. Paleobiology 25:44058

Wallace AR. 1876. The Geographical Distribution of Animals. New York: Harpers 
Ward PD, Hurtado JM, Kirschvink JL, Verosub KL. 1997. Measurements of the Cretaceous paleolatitude of Vancouver Island: consistent with the Baja-British Columbia hypothesis. Science 277:1642-45

Wiley EO. 1988a. Parsimony analysis and vicariance biogeography. Syst. Zool. 37:27190

Wiley EO. 1988b. Vicariance biogeography. Annu. Rev. Ecol. Syst. 19:513-42

Wiley EO, Mayden RL. 1985. Species and speciation in phylogenetic systematics, with ex- amples from the North American fish fauna. Ann. Mo. Bot. Gard. 72:596-635

Wiley EO, Siegel-Causey D, Brooks DR, Funk VA. 1991. The Compleat Cladist. Lawrence, KS: Univ. Kansas Press

Zink RM. 1996. Comparative phylogeography in North American birds. Evolution 50:30817

Zink RM, Blackwell-Rago RC, Ronquist F. 2000. The shifting roles of dispersal and vicariance in biogeography. Proc. R. Soc. London Ser. B 267:497-503 
R Annual Review of Ecology, Evolution, and Systematics

Volume 34, 2003

\section{Contents}

EFFECTS OF INTRODUCED BEES ON NATIVE ECOSYSTEMS, Dave Goulson

AVIAN SEXUAL Dichromatism IN RELATION TO PHYLOGENY AND

ECOLOGY, Alexander V. Badyaev and Geoffrey E. Hill

PAleobiogeography: The ReleVANCE of Fossils to BIOGEOGRAPHY, Bruce S. Lieberman

THE ECOLOGY OF BIRD INTRODUCTIONS, Richard P. Duncan, Tim M. Blackburn, and Daniel Sol

THE EFFECTS OF GENETIC AND GEOGRAPHIC STRUCTURE ON NEUTRAL VARIATION, Brian Charlesworth, Deborah Charlesworth, and Nicholas H. Barton

DATA, MODELS, AND DECISIONS IN US MARINE FISHERIES MANAGEMENT: LESSONS FOR ECOLOGISTS, Kenneth A. Rose and James H. Cowan Jr.

PARTITIONING OF TIME AS AN ECOlOGICAL RESOURCE, Noga Kronfeld-Schor and Tamar Dayan

PERFORMANCE COMPARISONS OF CO-OCCURING NATIVE AND ALIEN INVASIVE PLANTS: IMPLICATIONS FOR CONSERVATION AND Restoration, Curtis C. Daehler

GENETIC VARIATION IN RARE AND COMMON PLANTS, Christopher T. Cole

THE ECOLOGY AND EVOLUTION OF INSECT BACULOVIRUSES, Jenny S. Cory and Judith H. Myers

LATITUdinAl GRADIENTS OF BIODIVERSITY: PATTERn, PROCESS, SCALE, AND SYNTHESIS, M.R. Willig, D.M. Kaufman, and R.D. Stevens

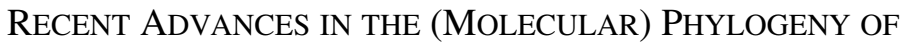
VERTEBRATES, Axel Meyer and Rafael Zardoya

THE ROLE OF REINFORCEMENT IN SPECIATION: THEORY AND DATA, Maria R. Servedio and Mohamed A.F. Noor

EXTRA-PAIR PATERNITY IN BIRDS: CAUSES, CORRELATES, AND

CONFLICT, David F. Westneat and Ian R.K. Stewart 
SPeCies-LeVel Paraphyly and Polyphyly: FreQuency, Causes, AND CONSEQUENCES, WITH INSIGHTS FROM ANIMAL

MitOCHONDRIAL DNA, Daniel J. Funk and Kevin E. Omland

Protective ANT-Plant INTERACTIONS AS Model SySTEMS IN

ECOLOGICAL AND EVOLUTIONARY RESEARCH, Martin Heil and Doyle McKey

FunCTIONAL MATRIX: A CONCEPTUAL FRAMEWORK FOR PREDICTING Plant EFFECTS ON ECOSYSTEM PROCESSES, Valerie T. Eviner and F. Stuart Chapin III

EFFECTS OF HABITAT FRAGMENTATION ON BIODIVERSITY, Lenore Fahrig

SOCIAL ORGANIZATION AND PARASITE RISK IN MAMMALS:

INTEGRATING THEORY AND EMPIRICAL STUDIES, Sonia Altizer, Charles L. Nunn, Peter H. Thrall, John L. Gittleman, Janis Antonovics, Andrew A. Cunnningham, Andrew P. Dobson, Vanessa Ezenwa, Kate E. Jones, Amy B. Pedersen, Mary Poss, and Juliet R.C. Pulliam

The COMMunity-LeVEl CONSEQUENCES OF SEED DisPeRSAL PATTERNS, Jonathan M. Levine and David J. Murrell

The ECOlOGY AND Evolution of SeEd DisPersal: A TheORETICAL PersPeCtIVE, Simon A. Levin, Helene C. Muller-Landau, Ran Nathan, and Jérôme Chave

ANALYSIS OF RATES OF MORPHOLOGIC EVOLUTION, Peter D. Roopnarine

605

DEVElOPMENT AND THE GENETICS OF EVOlutionaRy CHANGE Within Insect SPECIES, Paul M. Brakefield, Vernon French, and Bas J. Zwaan

FLEXIBILITY AND SPECIFICITY IN CORAL-ALGAL SYMBIOSIS: DIVERSITY, ECOLOGY, AND BIOGEOGRAPHY OF SYMBIODINIUM, Andrew C. Baker

INDEXES

Subject Index

Cumulative Index of Contributing Authors, Volumes 30-34

Cumulative Index of Chapter Titles, Volumes 30-34

708

\section{ERRATA}

An online log of corrections to Annual Review of Ecology,

Evolution, and Systematics chapters may be found at

http://ecolsys.annualreviews.org/errata.shtml 